\title{
A preservação do ato cooperativo de entrega ou recebimento na Lei 13.288/2016
}

\author{
The preservation of the cooperative act of delivery or receipt in Law $\mathbf{1 3 . 2 8 8 / 2 0 1 6}$
}

\begin{abstract}
Resumo
A Lei 13.288/2016, que dispõe sobre o contrato de integração agroindustrial, excluiu do seu regime as integrações praticadas por cooperativas sem haver registro das justificativas no processo legislativo. O objetivo desta pesquisa consiste na identificação das razões que justificam a exclusão das cooperativas do regime jurídico da integração agroindustrial. Para consecução deste objetivo, foram realizadas pesquisas documental e bibliográfica, consultando-se artigos científicos, projetos de lei, leis, decisões judiciais e administrativas, e livros das áreas de cooperativismo, organizações industriais, integração agroindustrial e tributação de cooperativas. A partir da leitura das fontes primárias e da revisão bibliográfica, o presente texto concluiu pela existência de três razões para a opção legislativa em questão. A primeira razão é a diferença da natureza entre o vínculo contratual entre o produtor integrado e o integrador e o vínculo societário nas cooperativas. A segunda razão é a inaplicabilidade dos mecanismos de contenção da dependência econômica e assimetria informacional da Lei 13.288/2016 às cooperativas, que enfrentam problemas de incentivo. A terceira razão é a concretização do "adequado tratamento tributário ao ato cooperativo" pela não incidência da contribuição previdenciária prevista na Lei 8.212/1991.
\end{abstract}

Palavras-chave: agroindústria cooperativa; contrato de integração agroindustrial; problemas de incentivo; adequado Tratamento tributário

\begin{abstract}
The Law 13.288/2016, which deals with the contract farming, excluded from its regime the integrations practiced by cooperatives without reasons' records in the legislative process The objective of this research is to identify the reasons that justify the exclusion of cooperatives from the legal regime of agro-industrial integration. In order to achieve this objective, documentary and bibliographic research was carried out, consulting scientific articles, bills, laws, judicial and administrative decisions, and books in the areas of cooperatives, industrial organizations, agro-industrial integration and cooperatives taxing. From reading the primary sources and bibliographic review, his text concluded that there are three reasons for this legislative option. The first reason is the difference in nature between the contractual link between the integrated producer and the integrator and the corporate link in the cooperatives. The second reason is the inapplicability of the mechanisms of the containment of the abuse of economic dependence and informational asymmetry of Law 13.288/2016 to the cooperatives, which face incentive problems. The third reason is the implementation of the "adequate tax treatment to the cooperative act" due to the non-incidence of social security contribution provided for in Law 8.212/1991.
\end{abstract}

Keywords: cooperative agroindustry; farming contract; incentive issues; proper tax treatment

Gabriel Fernandes Khayat ${ }^{\mathrm{I}}$

I Faculdade de Direito de Ribeirão Preto da Universidade de São Paulo, gabriel.khayat@usp.br 


\section{Introdução}

Desde 1998 tramitaram no Congresso Nacional diversos Projetos de Lei para estabelecer um regime jurídico próprio aos contratos de integração agroindustrial, que os diferenciassem dos contratos agrários típicos previstos no Estatuto da Terra (ET). A partir dos Projetos de Lei no 330/2011 e 8.023/2010, que culminaram na Lei 13.288/2016, as cooperativas foram afastadas da incidência de um regramento especial, sem que tivesse sido registrada a justificativa para tanto nos respectivos históricos legislativos na Câmara dos Deputados e Senado Federal.

Com a publicação e vigência da Lei 13.288/2016 (LIntegr), que, ao dispor sobre o contrato de integração agroindustrial nas atividades agrossilvipastoris, em seu parágrafo único do artigo $\mathbf{1}^{\mathbf{0}}$, caracterizou a integração praticada por cooperativas como ato cooperativo sujeito à Lei 5.764/1971 (LCoop), esperava-se que a doutrina jurídica perquirisse as razões para esta opção legislativa, articulando os traços identitários e desafios próprios do cooperativismo agroindustrial. Contudo, não foi isto o que se sucedeu até então.

Os juristas concentraram os esforços para compreender os complexos mecanismos de contenção do abuso de dependência econômica estabelecidos pela LIntegr, de modo que o parágrafo único, do artigo $1^{\circ}$, não tem sido objeto de análises aprofundadas, mas de simples paráfrase do texto legal, sem enfrentar os aspectos identitários e econômicos próprios do cooperativismo que justificam a preservação do ato cooperativo enquanto tal.

Em razão desta lacuna doutrinária, considerando o relevante papel das cooperativas nas atividades integradas, especialmente no processamento de carne de aves e porcos em Santa Catarina e na produção de leite no Paraná (BIALOSKORSKI NETO, 2011), o presente texto justifica sua importância, ao traçar como objetivo a identificação das razões que justificam a exclusão das cooperativas do regime jurídico da integração agroindustrial conforme determinado pelo parágrafo único, do artigo $1^{\circ}$, da Lei 13.288/2016.

Além da manutenção dos incentivos fiscais ao cooperativismo (MCNAUGHTON, 2007), como determina a Constituição Federal de $1988(C F)$ ao prever o adequado tratamento tributário ao ato cooperativo no artigo 146, III, "c", $C F$, considera-se como hipótese que o afastamento da incidência da Lei 13.288/2016 das integrações praticadas pelas cooperativas também se justifica por conta dos seus traços característicos que as tornam diferentes das demais organizações.

\section{Procedimentos Metodológicos}

Para consecução do objetivo consistente na identificação das razões que justificam a exclusão das cooperativas do regime jurídico da integração agroindustrial, foi utilizada a metodologia de pesquisa documental, que segundo Marconi e Lakatos (2010), consiste no levantamento de fontes primárias, ainda não analisadas cientificamente ou empiricamente.

Neste sentido, os documentos consultados foram projetos de lei, leis e instruções normativas, aplicáveis à integração agroindustrial praticada por cooperativas e a jurisprudência formada pelo conjunto de decisões judiciais e administrativas que constituem entendimento sobre as referidas normativas ao caso concreto, pois se tratam de fonte escritas públicas aptas a compreender a construção e definição do ambiente institucional em que as cooperativas realizam integração agroindustrial.

Além do procedimento metodológico acima, foi utilizada a pesquisa bibliográfica, que, neste caso, compreendeu a consulta aos textos que debatem o arranjo das cooperativas na integração agroindustrial sob o ponto de vista de sua organização e a sua caracterização jurídica, a partir de publicações científicas, como livros, periódicos, imprensa escrita, enquanto dados indiretos (MARCONI; LAKATOS, 2010).

A combinação da pesquisa documental, pela consulta à legislação e jurisprudência, com a pesquisa bibliográfica de publicações científicas, como procedimento metodológico, foi escolhida por permitir identificar as razões que justificam a exclusão das cooperativas do regime jurídico da integração agroindustrial conforme determinado pelo parágrafo único, do artigo $\mathbf{1}^{\mathbf{0}}$, da Lei 13.288/2016. 
Isso porque a legislação e a jurisprudência apontam para as consequências tributárias da caracterização da integração agroindustrial praticada por cooperativas e o desalinhamento dos mecanismos previstos na Lei 13.288/2016 para a realidade das cooperativas, enquanto a revisão bibliográfica identifica os desafios do cooperativismo agroindustrial, especialmente no arranjo de interesses e coordenação entre cooperativa e cooperado, que diferem da relação contratual entre produtor integrado e integrador.

Para a realização desta pesquisa, foram consultados 13 (treze) artigos científicos publicados em revistas e anais de congressos, uma tese, 2 (duas) decisões administrativas, 1 (um) acórdão judicial, 5 (cinco) leis, 4 (quatro) projetos de lei, uma instrução normativa, e 19 (dezenove) livros das áreas de cooperativismo, organizações industriais, integração agroindustrial e tributação de cooperativas, a partir da consulta da obra de autores reconhecidos nesta áreas, como Bialoskorski Neto, Diva Benevides Pinho, Décio Zylbersztajn, Kassia Watanabe, Walmor Franke e Renato Lopes Becho.

\section{O fenômeno econômico da integração agroindustrial}

Os arranjos econômicos mais frequentemente visualizados nos setores agroindustriais que transacionam ativos específicos são relações contratuais de longo prazo com adensamento obrigacional que permitem produção homogênea e com padrões de qualidade (UNIDROIT; FAO; FIDA, 2018). Contudo, no Brasil, nem sempre as relações contratuais tiveram o mesmo grau de sofisticação como é verificado atualmente.

A partir do modelo americano do "contract farming" e do processamento de legumes na Europa, em especial na Holanda e na França, o Brasil incorporou definitivamente o modelo de integração agroindustrial à produção avícola no oeste catarinense na década de 1960 (PAIVA, 2010). Antes disso, a integração agroindustrial foi praticada na década de 1920 no Rio Grande do Sul no cultivo de fumo (WATANABE; PAIVA; LOURENZANI, 2017). Hoje, o modelo econômico da integração agroindustrial é também utilizado na produção de leite (WATANABE; LOURENZANI; BANKUTI, 2017) e no cultivo de maçãs e uvas (PAIVA, 2010).

Para estímulo ao desenvolvimento nos sistemas de produção integrada e manuais de orientação dos produtores integrados, para conscientização sobre os seus direitos e riscos envolvidos na integração agroindustrial (UNIDROIT; FAO; FIDA, 2018), a Organização das Nações Unidas para a Alimentação e a Agricultura (FAO), o Fundo Internacional de Desenvolvimento Agrícola (IFAD) e a Instituto Internacional para a Unificação do Direito Privado (UNIDROIT) editam "guidelines".

Os documentos disponibilizados pelos referidos órgãos e agências são importante fonte de pesquisa de direito comparado para aplicação de técnicas desenvolvidas em ordenamentos jurídicos diversos para equalização de assimetrias na integração agroindustrial. O estudo destes materiais permite não só a uniformização da integração agroindustrial, mas também a adaptação de soluções estrangeiras para a realidade nacional, o que não é o objetivo deste texto.

A integração agroindustrial é o modelo vencedor apto a atender as demandas do mercado consumidor, especialmente com relação à qualidade do produto, segurança alimentar e responsabilidade ambiental, pois permite a agroindústria planejar e organizar a sua produção, o que evidentemente depende de um fluxo contínuo de abastecimento de matéria-prima homogênea, de acordo com sistemas de produção certificados (BIJMAN, 2009).

Para alcançar a regularidade e a qualidade de fornecimento, ao invés de internalizar a produção via relações hierárquicas e societárias, a agroindústria pratica a denominada quaseintegração (JANNARELLI, 2011), pelo que destaca parcela da cadeia produtiva a ser exercida pelo produtor sob o comando e orientação técnica da indústria processadora, afastando-se assim dos riscos trabalhistas, de mercado, sanitários e ambientais que tradicionalmente caracterizam a atividade agrária (UNIDROIT; FAO; FIDA, 2018).

Neste arranjo, o produtor recebe treinamentos e qualificações, além de insumos, sementes e crias para o desenvolvimento de determinado ciclo biológico, ou mesmo financiamentos e adiantamentos financeiros garantidos pela indústria processadora. Após a engorda, criação ou cultivo, o produtor coloca os produtos agrários por ele desenvolvidos à disposição da indústria 
processadora, que realizará os atos de beneficiamento e processamento para posterior comercialização e distribuição junto ao mercado consumidor (CASSI, 2014).

A integração agroindustrial é fruto de um novo arranjo econômico projetado pelo capitalismo de concentrações (ZELEDÓN, 1990), em que se busca o controle do elo estratégico da cadeia, no caso, o beneficiamento e processamento da matéria-prima para comercialização. No Brasil, a integração agroindustrial se consolida definitivamente como sistema de governança para as transações agroindustriais a partir da década de 1990, com a estabilização econômica e abertura do mercado para a concorrência estrangeira, o que forçou a reestruturação tecnológica das agroindústrias nacionais.

O fenômeno econômico da integração agroindustrial pode ser visualizado em duas situações distintas: (i) por arranjos estabelecidos entre o produtor integrado e a indústria processadora, que é o próprio contrato de integração agroindustrial regulado pela Lei $13.288 / 2016$, ou (ii) pela relação societária entre o produtor cooperado e a cooperativa processadora, com natureza jurídica de ato cooperativo (THAME, 1984).

Portanto, a integração agroindustrial, enquanto relação estabelecida entre dois agentes econômicos na qual há o destaque de parte da cadeia produtiva a ser realizado por um destes agentes, pode se estruturar em duas formas de governança: (i) hierárquica, quando ocorre no ambiente cooperativo, via "ato cooperativo", ou (ii) híbrida, quando ocorre a partir de contrato de integração agroindustrial, que em vista de sua natureza relacional implica adensamento de vínculo obrigacional superior à simples relação de mercado.

\section{A integração na agroindústria cooperativa}

As cooperativas praticam integração agroindustrial na medida em que fornecem insumos e promovem serviços técnicos de interesse comum aos cooperados, assumindo a distribuição e comercialização dos produtos entregues após o devido processo de beneficiamento e industrialização (PINHO, 1984).

Neste sentido, Gustavo Saad Diniz (2019) explica que os produtores cooperados entregam a produção para a cooperativa, que prestará os serviços de venda, com a vantagem competitiva de poder de barganha perante o mercado, ao mesmo tempo em que pode vender-lhes insumos, e prestar treinamentos e assistência social, como se pode visualizar na imagem abaixo:

Figura 1 - Integração Agroindustrial nas Cooperativas

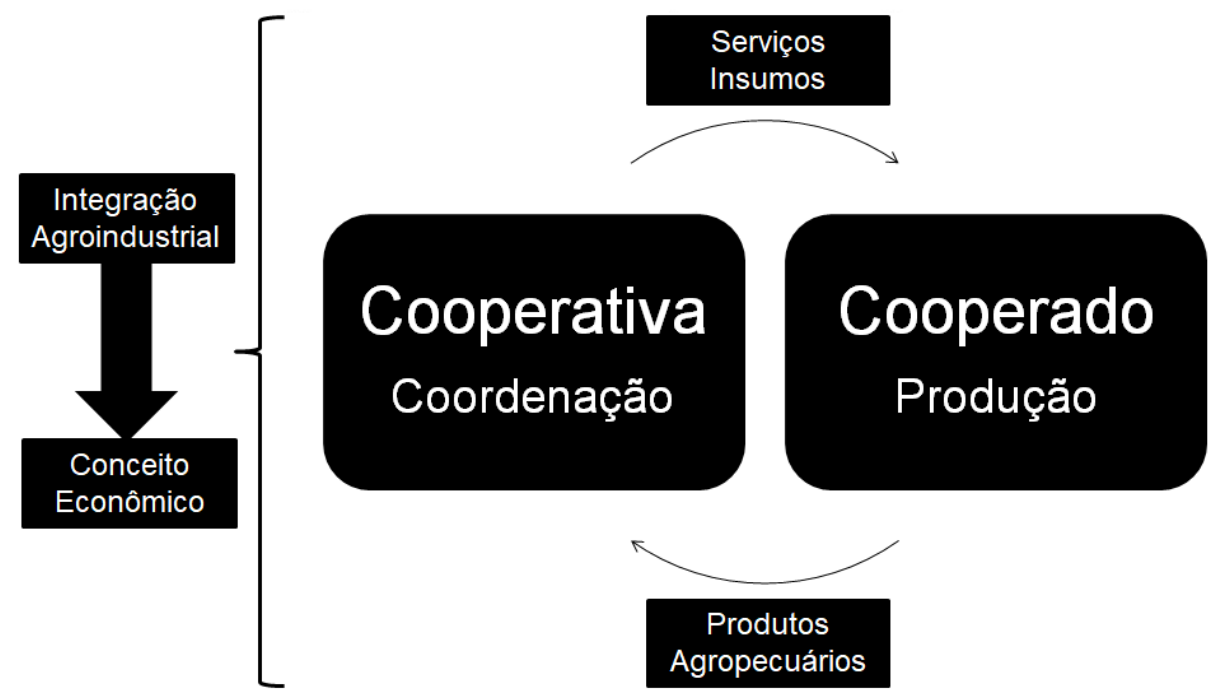

Fonte: Autor, 2019.

A formatação jurídica das relações estabelecidas entre cooperativa e cooperados permite definir as cooperativas agroindustriais como um modelo de governança que coordena a produção 
dos cooperados, então independentes, para organizar a sua atividade em um arranjo que lhes confira mais competividade, assentada em princípios como igualdade, equilíbrio e colaboração entre as atividades individuais em vista de um ganho de eficiência coletiva.

A eficiência decorre do encadeamento e distribuição de atividades entre cooperados e cooperativas. As transações praticadas por cada um dos cooperados, antes independentes entre si, adquirem uma feição sequencial e interdependente, pelo que as cooperativas são qualificadas como "organizações econômicas intermediárias" (BIJMAN, 2009), que, ao assim proceder, reduzem os custos pela utilização mais completa dos fatores de produção empregados (KOLLER, 1950).

Assim, as cooperativas manejam a economia individual dos cooperados com o mercado (BIALOSKORSKI NETO, 2011) ao organizar os serviços prestados aos seus agricultores associados e integrar as suas atividades, o que gera ganhos de economia de escala em dois aspectos (BIJMAN, 2009). A soma das economias particulares conferem melhores condições para negociar a venda dos produtos no mercado (BIALOSKORSKI NETO, 2011) e adquirir insumos (PINHO, 1984), facilitando, inclusive, a obtenção de ativos específicos e informações estratégicas, o que atenua a assimetria informacional tradicional entre produtor e indústria processadora (BIJMAN, 2009).

A integração praticada pelas cooperativas também permite o acesso do produtor ao mercado em uma situação de maior equidade nas negociações e maior poder de barganha quando comparada com a realidade da integração agroindustrial praticada via contratos (KOLLER, 1950). Na medida em que os cooperados entregam a produção para a cooperativa, rompe-se a dificuldade do produtor integrado com pouquíssimo poder de barganha que se submete às condições impostas pelo integrador, atenuando os riscos de dependência econômica por investimentos específicos (BIJMAN, 2009).

Em contrapartida aos ganhos indicados, o fato é que no jogo de interesses entre produtor cooperado e agroindústria cooperativa, prevalecerá sempre o da última, que buscará a mitigação dos próprios riscos em detrimento do preço do produto para alcançar um retorno líquido rentável, até porque a agroindústria cooperativa precisará competir com a agroindústria empresarial para se manter no mercado (PINHO, 1984).

Portanto, a integração agroindustrial praticada por cooperativas emoldura um complexo arranjo de interesses entre o cooperado-integrado e a cooperativa-integradora. Os ganhos e conflitos próprios desta relação estão no cerne do parágrafo único do artigo $1^{\circ}$ da Lei 13.288/2016, que expressamente afastou a aplicação da LIntegr às cooperativas, embora estas pratiquem verdadeira integração agroindustrial do ponto de vista econômico.

\section{A natureza própria do ato cooperativo e o contrato de integração agroindustrial}

Atualmente, as organizações são visualizadas juridicamente a partir das atividades que desempenham. O Código Comercial de 1850, contudo, definia os atos isolados, especialmente para identificar a figura do comerciante por meio dos chamados "atos de comércio". Em paralelo a esta legislação, o artigo 79, da Lei 5.764/1971, definiu as operações das cooperativas como "atos cooperativos", ao que a doutrina passou a distinguir dos chamados "atos não cooperativos" (DINIZ, 2019).

Segundo a Lei 5.764/1971, os atos cooperativos são todos aqueles praticados pelas cooperativas com os seus associados e entre cooperativas para a consecução dos objetivos sociais, ou seja, são os negócios internos da cooperativa. A negociação da cooperativa com terceiros, por sua vez, seria autorizada desde que para atender os mesmos objetivos sociais, conforme se infere do artigo 86, da Lei 5.764/1971.

Walmor Franke (2009) diferencia o ato cooperativo objeto do artigo 79, da Lei 5.764/1971, do ato não cooperativo, autorizado pelo artigo 86, da Lei 5.764/1971, enquanto negócio-fim e negóciomeio, respectivamente. $\mathrm{O}$ ato cooperativo é um negócio-fim porque se justifica pelo objetivo social desempenhado por determinada cooperativa, e só podem ser compreendidos de acordo com as normas estatuárias. Já o negócio-meio é a relação estabelecida pela cooperativa diretamente com o mercado e de acordo com as suas regras, portanto são negócios externos à cooperativa. 
Portanto, para Walmor Franke (2009), o conceito de "ato cooperativo" representa as operações internas da cooperativa entre os cooperados e a cooperativa ou entre cooperativas, compreendidos no limite das normas estatutárias. Dos atos cooperativos, são produzidos efeitos jurídicos que se encadeiam para a realização do negócio-fim, a partir do feixe de direitos e deveres entre a cooperativa e os cooperados.

Na lógica da integração agroindustrial, o abastecimento da cooperativa pela matéria-prima e produtos agrários produzidos pelo cooperado trata-se do "ato cooperativo de entrega ou recebimento", assim definido por Walmor Franke (2009), na medida em que há transferência de ativos para alcançar os objetivos sociais definidos pela cooperativa, em conformidade com o artigo 79 da Lei 5.764/1971 (BECHO, 2002).

O fornecimento de insumos ao cooperado e a entrega da produção à cooperativa são os negócios principais, ao passo que o processamento para a comercialização destes produtos com terceiros são os negócios essenciais (ou negócio-meio) (BECHO, 2002), porquanto justificam a realização dos negócios internos (ou negócios-fim) (FRANKE, 2009).

A entrega da produção do cooperado à cooperativa desencadeia uma série de atos. A partir da entrega da produção, a cooperativa tem o poder-dever deverá processar esta produção ou encaminhar para que uma federação de cooperativa o faça. Com a venda da produção ao mercado, a cooperativa deverá restituir ao cooperado as sobras, obtida a partir do valor de venda, descontadas as despesas e deduções estatutárias (FRANKE, 2009).

No caso das cooperativas agroindustriais, todas as vezes que as cooperativas vendem a produção conjunta dos seus cooperados para indústrias processadoras ou colocam a matéria-prima já processada nos canais de distribuição, há ato não-cooperativo, que se justifica porquanto é meio para atender ao objetivo social da cooperativa, conforme autorizado pelo artigo 86, da LCoop.

Cumpre observar também que a eventual aquisição de produtos de terceiros não-cooperados para o desempenho dos negócios essenciais são atos não-cooperativos (BECHO, 2002), em razão da interpretação sistemática dos artigos 85 e 111, ambos da Lei 5.764/1971, que autorizam a aquisição de produtos fornecidos por produtores independentes não associados para completar lotes destinados ao cumprimento de contratos ou suprir capacidade ociosa de instalações industriais das cooperativas que as possuem.

A figura abaixo ilustra a natureza jurídica das transações praticas pela cooperativa agroindustrial, demonstrando que somente as operações realizadas entre os produtores cooperados e a cooperativa são caracterizados como atos cooperativos:

Figura 2 - Atos Cooperativos e Atos Não-Cooperativos na Cooperativa Agroindustrial

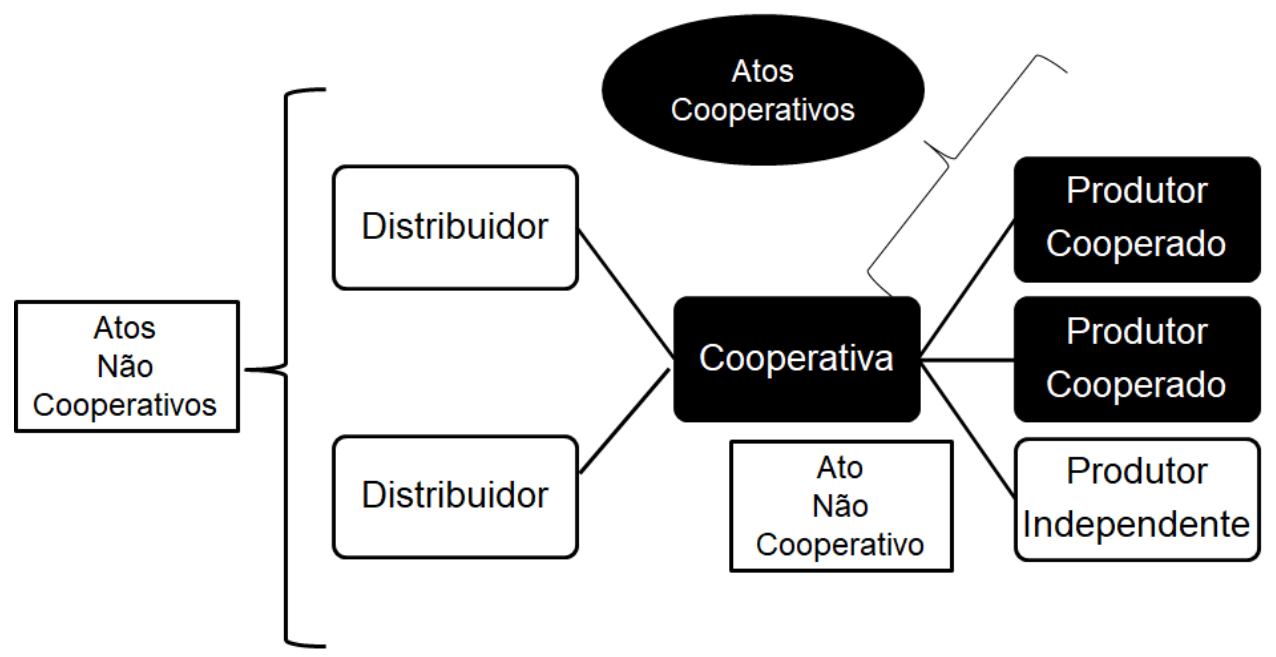

Fonte: Autor, 2019.

A diferenciação doutrinária entre os atos cooperativos e atos não-cooperativos feita a partir da interpretação da $L C$ oop aponta para a existência de traços e características próprios da relação 
estabelecida entre a cooperativa e seus cooperados, que justifica o afastamento da integração agroindustrial praticada pelas cooperativas do regime da Lei 13.288/2016.

Isso porque, enquanto ato cooperativo, a relação jurídica estabelecida entre o cooperadointegrado e a cooperativa-integradora é horizontalizada, e não verticalizada como ocorre na via contratual (WATANABE; PAIVA; LOURENZANI, 2017). Isto significa dizer que a integração agroindustrial formada por vínculo contratual é tensionada pelos interesses próprios de cada uma das partes, que buscam o lucro individual, muito embora o sucesso da operação seja benéfico tanto ao produtor integrado como ao integrador (WATANABE; PAIVA; LOURENZANI, 2017).

Nas cooperativas, contudo, há vínculo societário entre os cooperados, unidos e movidos pela consecução de um fim comum sem objetivo de lucro, ao menos segundo a definição legal prevista no artigo $3^{\circ}$ da Lei 5.764/1971 (RIZZARDO, 2017). Assim, o produtor-cooperado e a cooperativaintegradora não são contratantes com interesses opostos, mas interesses justapostos e orientados para a realização do objeto social decorrentes de um dever estatutário (FRANKE, 2009).

O vínculo societário entre a cooperativa e seus cooperados projeta direitos difusos, como a ausência de separação clara entre controle e propriedade e a impossibilidade de alienação do ativo em razão do artigo $4^{\circ}$, inciso IV, da $L C o o p$ que restringe as negociações das quotas-partes, cujo valor não aumenta proporcionalmente com o crescimento dos ativos da cooperativa (BIALOSKORSKI NETO, 2008).

Como se demonstrará adiante, este conjunto de direitos implica problemas de incentivo, que dependem de solução específica, o que demanda um conjunto de regras bem definidas, aceitas e respeitadas por todos os sujeitos, como elucidado por Elinor Ostrom nos estudos empíricos de gestão de bens comuns, especialmente no bojo dos arranjos cooperativos, como os casos das cooperativas de pesca e de extração de madeira (OSTROM, 2015).

Não obstante, as características distintivas e particulares do ato cooperativo apresentadas até então implicam a necessidade de análise da causa das obrigações. Os atos cooperativos de entrega ou recebimento, enquanto negócios-fim, são a causa dos negócios essenciais de processamento e comercialização dos produtos com terceiros (FRANKE, 2009).

A causa do ato cooperativo de entrega ou recebimento é o próprio dever estatuário, que desencadeia e interliga demais atos sequenciais e interdependentes dos outros produtorescooperados a fim de que a cooperativa-integradora receba os produtos por tradição e assim os processe para fins de comercialização.

Já os contratos de integração agroindustrial têm causa distinta. Além do papel de abastecimento do integrador, Nunziata Paiva (2010) apontou a função de coordenação do setor agrícola na medida em que desloca a etapa produtiva ao produtor integrado, que atua de modo coordenado com as demandas quantitativas e qualidades do integrador (PORRU, 1990).

As diferenças apontadas acima entre a natureza do ato cooperativo de entrega ou recebimento e o contrato de integração agroindustrial são uma das razões pela qual o legislador optou por afastar a incidência da Lei 13.288/2016 das integrações praticadas por cooperativas.

\section{$7 \mathrm{O}$ desalinhamento entre o interesse tutelado pela Lei 13.288/2016 e os problemas na agroindústria cooperativa}

As distinções entre o ato cooperativo e a integração contratual, bem como o escopo da Lei 13.288/2016, a tornam inaplicável às integrações cooperativas também sob o ponto de vista finalístico do interesse protegido pelo legislador, já que cada um destes arranjos apresenta pontos de atritos distintos que demandam soluções específicas. São distintos os desafios da integração agroindustrial praticada entre cooperativas agroindustriais e produtores cooperados daquela objeto do contrato de integração agroindustrial.

Internacionalmente, prevaleceu o consenso de que a integração agroindustrial, por ser relação econômica própria caracterizada pelo adensamento de vínculo obrigacional e para desenvolvimento de parte do ciclo biológico, deveria ser objeto de legislação específica por cada um 
dos países em que este sistema fosse preponderante, a fim de regular os pontos mais sensíveis e de maior tensão entre o produtor integrado e o integrador (ZELEDÓN, 1990).

O setor de integração agroindustrial no Brasil aguardou por cerca de 30 anos a edição de legislação específica, e ao fazê-lo, confiava na premissa de que um diploma normativo seria capaz de melhor definir o ambiente institucional, conferindo-lhe segurança jurídica para complementar as práticas comerciais sedimentadas e tornadas socialmente típicas desde a década de 1960 na criação de aves de corte (WATANABE; ZYLBERSZTAJN, 2014).

Os grupos de interesses que orientaram o percurso legislativo da LIntegr pautaram a discussão no sentido da necessidade de se reconhecer a situação de desvantagem do produtor integrado em relação à indústria processadora, por não deter conhecimento técnico para compreensão aprofundada de todos os aspectos relevantes no sistema de produção integrada, bem como por não gozar de poder de barganha suficiente para negociar melhores condições contratuais e assegurar o cumprimento do contrato.

O PL 4.378/1998 foi o primeiro projeto de lei, caracterizado por ser a versão mais protetiva ao produtor entre todos os textos, por determinar que a remuneração do produtor integrado deveria observar todos os seus custos de produção, composto pela mão-de-obra e investimentos de ativos, além de imputar a obrigação de que o integrador arcasse com o pagamento das apólices de seguro dos produtores, bem como realizassem as devidas contribuições previdenciárias (WATANABE; ZYLBERSZTAJN, 2014).

Ocorre que após esta sinalização de tutela específica ao produtor integrado, com a imposição de obrigações determinadas à indústria processadora, a tutela protetiva encontrou seu ponto de inflexão. Os rumores sobre a declarada proteção ao produtor integrado serviu de argumento para apontar um possível desincentivo do sistema de produção integrada, que poderia ser substituído pela internalização das atividades pelas próprias indústrias processadoras (WATANABE; ZYLBERSZTAJN, 2014).

Em razão disto, os projetos de lei subsequentes abandonaram a técnica de proteção específica aos produtores integrados, como a determinação de que a indústria processadora realizasse o pagamento das contribuições previdenciárias e seguro de vida dos produtores integrados, para então enfatizar a necessidade de assegurar o cumprimento do contrato, o que lançou luzes para as criações de entidades setoriais paritárias para discussão do sistema de integração agroindustrial e de mecanismos contratuais para aumento da transparência do contrato (SOPEÑA; ARBAGE; VAZ).

Neste sentido, destacam-se os PL 3.979/2008 e PL 8.023/2010, com a previsão do primeiro de constituição de instituições como o Fórum Nacional de Integração Agroindustrial (FONIAGRO) e Comissões de Conciliação e Arbitragem, ao passo que o segundo substituía as últimas pela Comissão de Acompanhamento e Desenvolvimento da Integração e de Solução de Controvérsias (CADISC), e mantinha o FONIAGRO.

O PL 8.023/2010 também previu a criação do Documento de Informação Pré-Contratual (DIPC) e do Relatório de Informações da Produção Integrada (RIPI) como mecanismos para materializar o dever de lealdade, derivado da boa-fé objetiva, na fase pré-contratual e a transparência no curso do desempenho das obrigações relativas ao sistema de produção integrada, respectivamente.

Observando a estrutura acima, foi apresentado o PL 330/2011, que efetivamente é a gênese da LIntegr com pequenas modificações em relação ao PL 8.023/2010. Assim, além de distribuir as obrigações contratuais, a Lei 13.288/2016 inovou ao prever a criação de entidades setoriais paritárias responsáveis pela definição do conteúdo contratual e prospecção de elementos para aperfeiçoamento da integração agroindustrial, bem como imputar a obrigação de circular instrumentos como o DIPC e RIPI para assegurar transparência ao produtor integrado.

Neste contexto, ao invés da legislação brasileira definir de antemão todo o conteúdo obrigacional desejado para cada uma das partes, lançou mão da técnica de "standards", pela qual emoldurou padrões e definiu limites para a autonomia privada no preenchimento do conteúdo contratual. Deste modo, ao contrário do Estatuto da Terra, a legislação do contrato de integração agroindustrial conferiu flexibilidade aos particulares, permitindo que o contrato refletisse a realidade de cada uma das atividades agrossilvipastoris que podem ser praticadas em sistema de integração agroindustrial (BUENO, 2017) 
Portanto, o interesse tutelado da Lei 13.288/2016 consiste no combate à assimetria informacional entre indústria processadora e produtor integrado, a tutela das situações de abuso de dependência econômica do produtor integrado, de modo a garantir o mínimo de condições para que o contrato seja negociado em bases equilibradas e assentado em premissas comuns às partes, facilitando, inclusive o seu cumprimento.

Como já enunciado, para acompanhar o sistema de integração para fins de assegurar o enforcement contratual, a LIntegr criou fóruns setoriais paritários formados pelos produtores integrados e integradores, como o Fórum Nacional de Integração, estabelecido nos artigos $5^{\circ}$ e 12 da Lei 13.288/2016, e a as Comissões para Acompanhamento, Desenvolvimento e Conciliação da Integração, previstas nossa artigos $4^{\circ}$, incisos VII, VIII e XV, e 6º, da LIntegr.

Além das estruturas institucionais, para combater a assimetria informacional e assegurar transparência, a Lei 13.288/2016 criou instrumentos obrigatórios pelos quais o integrador apresenta as condições gerais de contratação no Documento de Informação Pré-Contratual (artigo 9º, da LIntegr)., e o Relatório de Informações da Produção Integrada (artigo $7^{\mathbf{o}}$, da LIntegr), com informações técnicas a respeito do sistema de integração.

Sem prejuízo destes mecanismos, a LIntegr ainda desenvolveu a técnica do conteúdo mínimo, pelo que a validade do contrato de integração agroindustrial depende do preenchimento de previsões obrigatórias, como a distribuição de responsabilidades tributária, organização de obrigações contratuais, definição do prazo para distribuição de resultado, e todas as demais previsões estabelecidas no artigo $4^{\circ}$, da LIntegr.

As partes contratantes tem liberdade para distribuir os riscos e deveres de acordo com o SAG envolvido e os seus interesses e pretensões. Dentre as cláusulas obrigatórias, destaca-se o artigo $4^{\circ}$, inciso XIV, da LIntegr, que determina a estipulação de aviso prévio para o encerramento do contrato para garantir o retorno dos investimentos realizados, preservando assim a viabilidade econômica do sistema de integração, regra semelhante ao parágrafo único, do artigo 473 do Código Civil.

Haja vistas as estruturas criadas pela LIntegr, o interesse tutelado da legislação é o combate ao abuso de dependência econômica, assimetria informacional e o risco do comportamento oportunista do integrador em face do produtor integrado, para assegurar poder de barganha aos produtores integrados e assegurar o cumprimento dos termos do contrato. Ocorre que as agroindústrias cooperativas atuam em ambiente institucional diverso, que tornam as técnicas criadas pela LIntegr inaplicáveis.

Isso porque nas integrações agroindustriais praticadas por cooperativas, os problemas visualizados na relação são de outra ordem. Primeiro porque o vínculo entre o cooperado e a cooperativa é mais duradouro do que o contrato de integração agroindustrial em razão da natureza societária, que é acentuado pelas restrições das negociações das quotas-partes previsto no artigo $4^{\circ}$, IV, da LCoop, o que afasta o risco da quebra contratual oportunista.

Embora também haja pesquisas que identifiquem disfunções associadas à transparência e aos investimentos específicos pelo cooperado-produtor (ZYLBERSZTAJN; SOUZA, 2011), a doutrina identifica com mais frequência e de modo mais claro nas cooperativas agroindustriais os problemas de incentivo (ZYLBERSZTAJN, 2005), que se formam pela falta de separação clara entre o poder de controle e a propriedade, de onde advém o ato cooperativo (DINIZ, 2017).

Ao contrário do que acontece na integração contratual, a agroindústria cooperativa não retira a possibilidade de tomada de decisões estratégicas pelo próprio produtor (PINHO, 1984). Neste cenário, o cooperado exerce um duplo papel na medida em que produz os produtos que serão entregues à cooperativa e também toma as decisões relativas a esta em assembleia-geral (ZYLBERSZTAJN, 2005), cujas deliberações são tomadas pelo cômputo dos votos "por cabeça", independentemente do volume de quotas ou transações em razão da singularidade do voto, previsto no artigo $4^{\circ}$, inciso $\mathrm{V}$, da $L C o o p$.

Diante desta situação, as cooperativas de integração agroindustrial estão diante de um problema de incentivo, eis que embora os cooperados possam estar engajados no incremento de sua estrutura produtiva para alcançar o sucesso da cooperativa, há uma tendência natural de o cooperado buscar seu ganho individual isoladamente e de forma imediata, em detrimento da eficiência econômica da cooperativa (BIALOSKORSKI NETO, 2011). Juridicamente, os problemas de 
incentivo são visualizados como conflito de interesses, matéria que ainda carece de debate profícuo nas ciências jurídicas.

O problema de incentivo se acentua com a integração da economia das cooperativas singulares às federações de cooperativas. Neste modelo, a cooperativa central tende a se dedicar prioritariamente à gestão econômica com a definição e operacionalização das estratégias de mercado (SOUSA; MACEDO; MILAGRES; COSTA, 2014), o que torna mais clara a definição dos interesses próprios contrapostos das cooperativas singulares e das federações.

Ocorre que o encadeamento frouxo e a má articulação da cadeia produtiva nestes arranjos escalonam os problemas de incentivo na medida em que distancia ainda mais o cooperado da tomada de decisão, já que este tem uma relação direta e imediata com a cooperativa singular, mas não com a cooperativa central, que está mais próxima das relações de mercado propriamente ditas, e assim atuam como organização econômica que busca a conquista de posição de mercado (SOUSA; MACEDO; MILAGRES; COSTA, 2014).

No bojo das cooperativas singulares, os problemas de incentivo também são ocasionados pelos aspectos financeiros por duas razões: invariabilidade do valor das quotas de acordo com o desempenho econômico da cooperativa (ZYLBERSZTAJN, 2005) e rateio das sobras pra rata após direcionamentos aos Fundos de Reserva e de Assistência Técnica Educacional e Social (FATES), como determinam os artigos $4^{\circ}$, incisos VII e VIII, e 44, inciso II, da LCoop (BIALOSKORSKI NETO, 2008).

Em razão disto, rompe-se o paradigma utópico de interesse comum entre cooperativa e cooperado, mormente porque se passa a questionar a efetiva participação do produtor na tomada de decisões complexas relativas ao processo de industrialização e distribuição, ou mesmo o conflito na definição do preço (PINHO, 1984), o que levaria o direcionamento da cooperativa a efetividade dos serviços prestados aos cooperados, e não à eficiência da operação (BIALOSKORSKI NETO, 2008).

Ocorre que a cooperativa não é uma estrutura à disposição do cooperado como "consumidor de serviços", mas uma organização com interesses próprios (BIALOSKORSKI NETO, 2006) dependente da equalização da adoção de estratégias competitivas (dimensão econômica) e a satisfação das demandas dos cooperados (dimensão social), que revela a dupla dimensão do cooperativismo, tensionada pela necessidade de conferir dinamismo às relações cooperativas ao mesmo tempo que não pode se render aos mecanismos próprios das sociedades empresárias, sob pena de descaracterização (SOUSA; MACEDO; MILAGRES; COSTA, 2014).

Isso porque, embora constituída e orientada por princípios solidários e de cooperação, o desenvolvimento da cooperativa depende do crescimento econômico e circulação de riquezas, com a estrutura de incentivos bem definida, até para evitar que os cooperados busquem outros meios de transação. Caso a cooperativa não mais forneça serviços e assistência social aos cooperados, estes naturalmente buscarão outros arranjos para viabilizar a sua produção, de modo a conferir-lhe maior retorno socioeconômico,

Em função destas circunstâncias próprias da cooperativa agroindustrial, como forma de fortalecimento do cooperativismo, o Professor Décio Zylbersztajn (2005) propõe a adoção de um programa de governança corporativa cooperativa, orientada pelo controle e sistema de informação a fim de solucionar os problemas decorrentes da nebulosa separação do poder controle e propriedade nas cooperativas.

Neste sentido, a gestão dos bens comuns na forma proposta por Elinor Ostrom (2015) indica que a propriedade e o controle não são bons elementos de governança na administração de recursos coletivos. Embora inexista um modelo único capaz de resolver a administração destes ativos, o arranjo dos interesses passa pela organização e cooperação para evitar a sobre-exploração e demarcação de princípios para definição de regras reconhecidas e aceitas por aqueles que exploram estes bens comuns.

No fundo, trata-se de modificações que buscam alcançar um padrão de gestão profissional e transparente, que identifica a deficiente comunicação e intercâmbio de informações entre os atores do cooperativismo como uma das razões para os problemas de incentivo e dificuldades de fidelização dos cooperados (SOUSA; MACEDO; MILAGRES; COSTA, 2014). Neste modelo, a transparência e a apresentação didática de informações aproxima o cooperado da tomada de decisão, estimulando a 
participação nas instâncias deliberativas, e, assim, permitindo que os interesses se orientem para a consecução de um mesmo fim.

De outro lado, o Professor Sigismundo Bialoskorski Neto (2008) sugere uma nova estrutura de tomada de decisão e capitalização para as cooperativas, ao que se chama de Nova Geração de Cooperativas (NGC). O modelo consiste na manutenção do igualitarismo e participação nas sobras pro rata, com a atribuição ao cooperado do direito de transacionar certa quantidade e qualidade de produtos com a cooperativa, o qual será passível de alienação. A proposta depende evidentemente de alterações legislativas, que colocariam em debate a manutenção dos princípios cooperativos.

Seja como for, independentemente de avaliação crítica a respeito dos caminhos apresentados pela doutrina, é evidente que as disfunções havidas nos contratos de integração agroindustrial, provocadas pela dependência econômica e assimetria informacional do produtor integrado, são muito diferentes daquelas visualizadas na integração cooperativa, que é a conciliação entre os interesses individuais dos cooperados e as estratégias de mercado das cooperativas (SOUSA; MACEDO; MILAGRES; COSTA, 2014), causados pelos problemas de incentivo.

Portanto, para situações distintas, são necessárias soluções individualizadas, pelo que a Lei 13.288/2016 também não poderia ser aplicada à realidade das cooperativas por criar mecanismos que não enfrentam o cerne dos conflitos próprios do cooperativismo. Além disso, nem mesmo por analogia, seria possível pensar na criação de fóruns setoriais no modelo proposto pela LIntegr para o cooperativismo. Assim, também sob este ponto de vista, a preservação do ato cooperativo na LIntegr se mostra adequada.

Contudo, isto não significa que os problemas de incentivo enfrentado no bojo das cooperativas agroindustriais devam ser ignorados, nem mesmo o debate sobre a transparência na composição do valor atribuído ao volume de produção entregue pelo produtor cooperado deve ser negligenciado. Se fechados os olhos para estes desafios, corre-se o risco de que as tensões nas relações contratuais de integração agroindustrial sejam equacionadas, enquanto o cooperativismo continue enfrentando as mesmas dificuldades.

\section{0 adequado tratamento tributário conferido ao ato cooperativo de entrega ou recebimento na agroindústria cooperativa}

A Constituição Federal, em seu artigo 146, inciso III, alínea "c" delegou à lei complementar a edição de regras destinadas à conferir e assegurar o "adequado tratamento tributário ao ato cooperativo praticado pelas sociedades cooperativas". Passados mais de 30 anos desde a vigência da $C F$, o sistema normativo brasileiro não conta com legislação específica para regular o adequado tratamento tributário ao ato cooperativo.

Em razão disso, a compreensão dos limites do que venha a ser o "adequado tratamento tributário" é traçado por outros dispositivos constitucionais que projetam o dever de incentivo estatal ao cooperativismo, expressamente previsto no Capítulo "Da Ordem Econômica e Financeira", no artigo 174, §2º, o que se desdobra na liberdade de associação, no artigo $5^{\circ}$, inciso XVIII, favorecimento da organização do garimpo em cooperativas pela prioridade para pesquisa e lavra, no artigo 174, $\S \S 3^{\circ}$ e $4^{\circ}$, observação do cooperativismo de crédito agrícola na definição da política agrícola e do sistema financeiro nacional, nos artigos 187 , inciso VI, e 192, respectivamente.

Neste cenário, o mandamento constitucional de "adequado tratamento tributário" é deslocado para as demais legislações, que devem sempre ter em vista o adequado tratamento tributário, o que evidentemente não tem o condão de conferir às cooperativas imunidade tributária, termo jurídico utilizado para designar as situações que não podem ser objeto de tributação previstas na Constituição Federal.

A noção de "adequado tratamento tributário" simplesmente obriga o legislador evitar que as cooperativas se submetam a um sistema de tributação mais oneroso do que as atividades econômicas organizadas sob outra roupagem. Além disso, cabe ao intérprete garantir a aplicação da legislação em conformidade com texto constitucional, sob pena de se subverter toda a lógica de incentivos ao cooperativismo (BECHO, 2005). 
Foi neste cenário, que ao definir a integração agroindustrial praticada por cooperativas e cooperados, bem como entre as cooperativas, a LIntegr mirou no artigo 25 da Lei no 8.212/1991, que cria a Contribuição Previdenciária para o Regime Geral de Previdência Social pela tributação sobre a receita bruta proveniente da comercialização da produção agrícola, conforme se pode verificar pela leitura da redação original do dispositivo legal em questão:

Art. 25. A contribuição do empregador rural pessoa física, em substituição à contribuição de que tratam os incisos I e II do art. 22, e a do segurado especial, referidos, respectivamente, na alínea a do inciso V e no inciso VII do art. 12 desta Lei, destinada à Seguridade Social, é de:

I - 1,2\% (um inteiro e dois décimos por cento) da receita bruta proveniente da comercialização da sua produção;

II - o,1\% da receita bruta proveniente da comercialização da sua produção para financiamento das prestações por acidente do trabalho.

(grifo nosso)

A Instrução Normativa RFB 971/2009, que dispõe sobre normas gerais de tributação previdenciária e de arrecadação das contribuições sociais destinadas à Previdência Social e as destinadas a outras entidades ou fundos, administradas pela Secretaria da Receita Federal do Brasil, esclarece o dispositivo acima ao prever que o fato gerador consiste apenas na comercialização da produção rural, excepcionando expressamente às cooperativas:

Art. 166. O fato gerador das contribuições sociais ocorre na comercialização:

I - da produção rural do produtor rural pessoa física e do segurado especial realizada diretamente com:

a) adquirente domiciliado no exterior (exportação), observado o disposto no art. 170;

b) consumidor pessoa física, no varejo;

c) adquirente pessoa física, não-produtor rural, para venda no varejo a consumidor pessoa física;

d) outro produtor rural pessoa física;

e) outro segurado especial;

f) empresa adquirente, consumidora, consignatária ou com cooperativa;

II - da produção rural do produtor rural pessoa jurídica, exceto daquele que, além da atividade rural, exerce atividade econômica autônoma do ramo comercial, industrial ou de serviços, observado o disposto nos $\S \S 4^{\circ}$ e $5^{\circ}$ do art. 175;

III - da produção própria ou da adquirida de terceiros, industrializada ou não, pela agroindústria, EXCETO QUANTO ÀS SOCIEDADES COOPERATIVAS E ÀS AGROINDÚSTRIAS DE PISCICULTURA, CARCINICULTURA, SUINOCULTURA E A DE AVICULTURA, a partir de 1 o de novembro de 2001.

Parágrafo único. O recebimento de produção agropecuária oriunda de outro país, ainda que o remetente seja o próprio destinatário do produto, não configura fato gerador de contribuições sociais.

(grifo nosso)

A redação dos dispositivos acima é suficientemente clara para concluir que o fato gerador da contribuição previdenciária em questão é a comercialização da produção rural, e, logicamente, a obtenção da receita, que é a base de cálculo do tributo, termo jurídico que compreende a grande econômica sobre a qual a alíquota incide para definição do valor do tributo. Portanto, por lógica, é possível concluir que sempre que não houver comercialização, assim entendida como a transferência da titularidade da produção agrícola mediante pagamento de preço, não há a incidência do artigo 25 da Lei no 8.212/1991.

$\mathrm{Na}$ integração agroindustrial praticada por cooperativas, deve-se considerar a natureza jurídica da circulação de produção agrícola. Como visto, as relações entre cooperativa e cooperados são qualificadas como ato cooperativo, em razão da natureza societária que não implica aquisição de produtos pelo pagamento de preço, mas comunhão de esforços em vista de ganhos de eficiência, seja pela prestação de serviços de venda conjunta da produção, seja pela aquisição conjunta de insumos. 
Ao reunir a produção e comercializar com terceiros, o cooperado não será remunerado pelo pagamento de preço, ou "valor de referência", segundo a dicção da LIntegr, mas de acordo com a lógica societária das cooperativas. Isso implica dizer que o cooperado será remunerado ao final do exercício pelo retorno das sobras líquidas do exercício proporcionalmente às operações realizadas, como previsto nos artigos 1.094, inciso VII, do Código Civil e $4^{\mathfrak{o}}$, inciso VII, da LCoop.

Portanto, ao contrário do que ocorre na integração agroindustrial por contratos, a cooperativa não adquire os produtos agrícolas de seus cooperados, mas reúne a produção individual de cada um dos cooperados para negociação no mercado, por se tratar de ato cooperativo. Deste modo, ao entregar a sua produção à cooperativa não há comercialização, pelo que não deveria incidir o fato gerador do artigo 25 da Lei no 8.212/1991, que não elegeu a mera transição de titularidade ou entrega da produção à cooperativa como fato gerador (TORRES, 2019).

Portanto, o parágrafo único, do artigo $1^{\circ}$, da LIntegr, foi editado justamente para afastar a incidência desta tributação sobre as agroindústrias cooperativas. Isso porque, ao caracterizar a integração agroindustrial praticada pelas cooperativas como ato cooperativo, a LIntegr automaticamente suscitou toda a carga legislativa da LCoop.

Neste sentido, ao definir o ato cooperativo, a LCoop, no parágrafo único, do artigo 79, expressamente explicitou que " $O$ ato cooperativo não implica operação de mercado, nem contrato de compra e venda de produto ou mercadoria". Ora, se a integração agroindustrial praticada pelas cooperativas é caracterizada como atos cooperativos, e como tal, não implicam operação de mercado ou compra e venda, evidentemente que não há comercialização, e por isso não incide o tributo previsto no artigo 25 da Lei no 8.212/1991.

A interpretação proposta, em conformidade com a determinação de adequado tratamento tributário, era majoritária no ordenamento jurídico até a edição da LIntegr, inclusive por orientação do Superior Tribunal de Justiça (STJ), que exerce a competência constitucional de uniformização jurisprudencial, e pacificou o entendimento de que a entrega da mercadoria pelo produtor rural à cooperativa, da qual é associado, não se confunde com a comercialização do produto por ela realizada, que constitui o fato gerador da contribuição previdenciária:

TRIBUTÁRIO E PROCESSUAL CIVIL. EXECUÇÃO FISCAL. EMBARGOS DO DEVEDOR. FUNRURAL. FATO GERADOR. COOPERATIVA. ATO DO COOPERATIVADO. REEXAME DE PROVA. IMPOSSIBILIDADE. SÚMULA O7/STJ.

1. Não se há de confundir a entrega da mercadoria pelo produtor rural à Cooperativa, da qual é associado, com a COMERCIALIZAÇÃO do produto por ela realizada, que constitui o fato gerador da contribuição previdenciária em causa. 2. Violação à lei federal não caracterizada.

3. Inadmissível o reexame de prova em sede de recurso especial. Aplicação de entendimento sumulado do STJ.

4. Recurso especial do qual não se conhece.

(BRASIL. Superior Tribunal de Justiça, Recurso Especial 248.073/RS, Ministro Relator Francisco Peçanha Martins, DJ 18/11/2002, grifo nosso)

A LIntegr, ao qualificar a integração agroindustrial praticada pelas cooperativas como ato cooperativo, apenas reforçou o entendimento de que a entrega da produção pelo cooperado à cooperativa não caracteriza comercialização, e por isso, não é passível de tributação na forma do artigo 25 da Lei no 8.212/1991. Portanto, o parágrafo único, do artigo $1^{\circ}$, da LIntegr também se justifica como comando destinado à garantir o adequado tratamento tributário previsto no artigo 146, III, "c", CF.

Curiosamente, contudo, ao analisar a integração agroindustrial praticada por cooperativas após consulta formulada por uma cooperativa, a Coordenação-Geral de Tributação da Receita Federal publicou a Solução de Consulta COSIT no 11/2017, concluindo que "toda a produção rural entregue à cooperativa, pelo cooperado, integra a produção para efeito da incidência da contribuição sobre a receita bruta da comercialização", nos seguintes termos:

CONTRIBUIÇÃO PREVIDENCIÁRIA SOBRE A RECEITA BRUTA DA COMERCIALIZAÇÃO DA PRODUÇÃO RURAL. COOPERATIVA DE PRODUTORES 


\section{RURAIS. CARACTERIZAÇÃO DE CONTRATO DE PARCERIA OU DE} INTEGRAÇÃO RURAL. IMPOSSIBILIDADE.

A entrega, pela cooperativa, de insumos ao cooperado e o recebimento, pela cooperativa, de toda produção rural do cooperado são consideradas relações jurídicas de natureza institucional da cooperativa, de modo que não cabe a caracterização do recebimento de parte da produção como sendo a título de participação da cooperativa em contrato de parceria ou integração rural, para efeito de afastar a incidência da contribuição sobre a receita bruta da comercialização da produção rural quanto à parte que caberia à cooperativa como fornecedora de insumos. A cooperativa fica sub-rogada na obrigação da contribuição previdenciária a cargo do produtor rural pessoa física ou segurado especial, devendo recolher esta contribuição sobre o valor da receita bruta da comercialização de toda produção que lhe é entregue pelo cooperado, até o dia 20 do mês subseqüente à operação de venda ou consignação.

DISPOSITIVOS LEGAIS: Lei no 8.212, de 1991, art. 25, art. 30, incisos III e IV; Lei

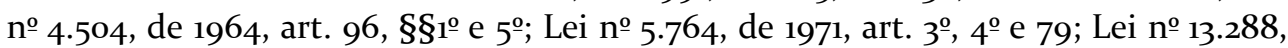
de 2016, art. $1^{\circ}$, parágrafo único; IN RFB no 971 , de 2009, art. 165, incisos XI a XIV e XXI; art.167, inciso III, art. 168 e art. 172, inciso I.

BRASIL. Coordenação-Geral de Tributação da Receita Federal. Solução de Consulta no $\quad 11 \quad-\quad$ Cosit. $\quad$ Disponível em: http://normas.receita.fazenda.gov.br/sijut2consulta/link.action?idAto=79703\&visao= anotado. Acesso em: 26.mai. 2019. (grifo nosso)

O entendimento acima consolida situação de evidente tratamento tributário desfavorável ao ato cooperativo, pois os cooperados terão que recolher tributação sobre o valor integral do produto final, enquanto nos contratos de integração agroindustrial, a base de cálculo compreende apenas o volume engordado.

Diante deste cenário desfavorável, a Organização das Cooperativas do Brasil (OCB) formulou nova consulta tentativa de reverter o entendimento, justificando a necessidade de se conferir o "adequado tratamento tributário" ao ato cooperativo em vista das peculiaridades que contornam a integração agroindustrial praticada por cooperativas. Contudo, o mesmo entendimento se manteve na Solução de Consulta DISIT/SRRFo6 no 6.026 publicada no dia 12/o7/2019:

CONTRIBUIÇÃO PREVIDENCIÁRIA SOBRE A RECEITA BRUTA DA COMERCIALIZAÇÃO DA PRODUÇÃO RURAL. COOPERATIVA DE PRODUTORES RURAIS. CARACTERIZAÇÃO DE CONTRATO DE PARCERIA OU DE INTEGRAÇÃO RURAL. IMPOSSIBILIDADE

A entrega, pela cooperativa, de insumos ao cooperado e o recebimento, pela cooperativa, de toda produção rural do cooperado são consideradas relações jurídicas de natureza institucional da cooperativa, de modo que não cabe a caracterização do recebimento de parte da produção como sendo a título de participação da cooperativa em contrato de parceria ou integração rural, para efeito de afastar a incidência da contribuição sobre a receita bruta da comercialização da produção rural quanto à parte que caberia à cooperativa como fornecedora de insumos.

A cooperativa está obrigada, por força dos incisos III e IV do art. 30 e do art. 25 da Lei no 8.212/1991, a recolher a contribuição social previdenciária incidente sobre a receita bruta proveniente da comercialização com base na integralidade da produção rural que a ela é repassada pelo cooperado

SOLUÇÃO DE CONSULTA VINCULADA À SOLUÇÃO DE CONSULTA COSIT № 11, DE 13 DE JANEIRO DE 2017

Dispositivos Legais: Lei no 8.212, de 1991, art. 25, art. 30, incisos III e IV; Lei no 4.504,

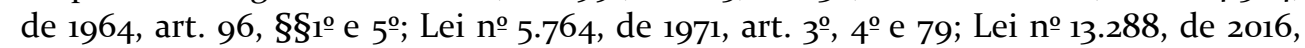
art. 1ㅜ, parágrafo único; IN RFB no 971, de 2009, art. 165, incisos XI a XIV e XXI.

BRASIL. Coordenação-Geral de Tributação da Receita Federal. Solução de Consulta no $\quad \mathbf{6 0 2 6} \quad$ - $\quad$ Disit. http://normas.receita.fazenda.gov.br/sijut2consulta/link.action?idAto=102261\&visao =anotado. Acesso em: 26. out. 2019. 
Com as decisões desfavoráveis à sua pretensão, o cooperativismo se organizou para obtenção de solução deste problema por alteração legislativa. Assim, a partir do trabalho da OCB junto ao Poder Legislativo (WALENDORFF, 2020), foi alterada a redação do artigo 25, da Lei no 8.212/1991 via edição da Medida Provisória no 899/2019, que modificou a redação do §3º e incluiu os $\$ \S 14$ ao 16 no referido dispositivo legal, que assim dispõem:

\begin{abstract}
Art. 25. (“omissis")
(...)

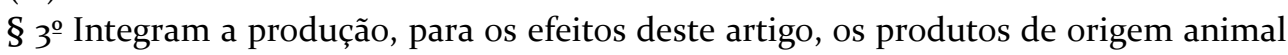
ou vegetal, em estado natural ou submetidos a processos de beneficiamento ou industrialização rudimentar, assim compreendidos, entre outros, os processos de lavagem, limpeza, descaroçamento, pilagem, descascamento, lenhamento, pasteurização, resfriamento, secagem, fermentação, embalagem, cristalização, fundição, carvoejamento, cozimento, destilação, moagem e torrefação, bem como os subprodutos e os resíduos obtidos por meio desses processos, exceto, NO CASO DE SOCIEDADES COOPERATIVAS, a parcela de produção que não seja objeto de repasse ao cooperado por meio de fixação de preço.

(...)

§ 14. Considera-se receita bruta proveniente da comercialização da produção o valor da fixação de preço repassado ao cooperado pela cooperativa ao qual esteja associado, por ocasião da realização do ato cooperativo de que trata o art. 79 da Lei no 5.764, de 16 de dezembro de 1971, não compreendidos valores pagos, creditados ou capitalizados a título de sobras, os quais não representam preço ou complemento de preço
\end{abstract}

$\S 15$. Não se considera receita bruta, para fins de base de cálculo das contribuições sociais devidas pelo produtor rural cooperado, a entrega ou o retorno de produção para a cooperativa nas operações em que NÃO OCORRA REPASSE PELA COOPERATIVA A TÍTULO DE FIXAÇÃO DE PREÇO, não podendo o mero retorno caracterizar permuta, compensação, dação em pagamento ou ressarcimento que represente valor, preço ou complemento de preço.

$\S 16$. Aplica-se ao disposto no caput e nos $\S \S 3^{\circ}$, 14 e 15 deste artigo o caráter interpretativo de que trata o art. 106 da Lei ${ }^{\circ}$ 5.172, de 25 de outubro de 1966 (Código Tributário Nacional)."(grifo nosso)

Como se pode verificar pela nova redação do artigo 25, da Lei no 8.212/1991, foi expressamente excepcionada da base de cálculo as parcelas de produção transacionadas entre cooperativas e entre cooperativas e cooperados que não haja fixação de preço. Em outas palavras, o que a Medida Provisória no 899/2019 modificou no ambiente institucional foi excluir da tributação os retornos e transações internas às cooperativas qualificados como ato cooperativos.

Deste modo, apenas as transações que ocorram via preço, isto é, que sejam efetivamente uma comercialização são passíveis de tributação, tendo como base de cálculo o valor da fixação de preço repassado. Os atos cooperativos de entrega e recebimento que serão apurados futuramente a partir da distribuição das sobras foram excluídos da tributação, para que fosse resguardado o "adequado tratamento tributário ao ato cooperativo".

Pelo fato desta nova redação ter sido incluída em Medida Provisória, espécie normativa editada precariamente pela Presidência da República, a sua validade dependerá de aprovação pelo Congresso Nacional e posterior sanção presidencial. Portanto, os operadores do direito devem estar atentos a estas modificações, bem como de sua aplicação retroativa, isto é, se poderá desonerar as operações já tributadas.

Se consolidada a alteração legislativa, não pode prevalecer o entendimento de que toda a circulação da produção nas cooperativas compõe a base de cálculo do artigo 25 da Lei no 8.212/1991, sob pena de consolidação de interpretação desalinhada com a lógica própria da integração agroindustrial praticada no bojo das cooperativas, que estarão submetidas a uma situação de tratamento mais gravoso ao ato cooperativo, em completa violação ao mandamento constitucional do "adequado tratamento tributário". 
Isso porque, ao contrário das cooperativas, nos sistemas de produção integrada estruturados por contratos agroindustriais, tem-se reconhecido que a circulação da produção entre produtor integrado e integrador não constitui comercialização, mas consequência das obrigações que caracterizam a integração agroindustrial.

Assim, apesar dos recentes entendimentos desfavoráveis e contrários à realidade jurídica das cooperativas, pode-se concluir que a redação do parágrafo único, do artigo $1^{\circ}$, da LIntegr se justifica em vista do "adequado tratamento tributário" como reforço normativo do entendimento então vigente de que a entrega da produção do cooperado à cooperativa não constitui comercialização, e portanto, não incide o artigo 25 da Lei no 8.212/1991.

\section{Conclusões}

Como visto, a integração agroindustrial entre cooperado e cooperativa poderia ser submetida ao regime da LIntegr por se tratar de fenômeno econômico. Contudo, por expressa disposição legal, exclui-se a integração entre cooperativa e cooperados, que permanece sujeita ao ato cooperativo e sistema do artigo 79, da Lei 5.764/71, conforme a redação do artigo 1ํㅡ, parágrafo único, da LIntegr. A determinação legal se justifica por pelo menos três razões.

$\mathrm{O}$ ato cooperativo de entrega ou recebimento tem como causa o dever estatutário, que horizontaliza a relação entre produtor e integrador formando um todo unitário, ao passo que o contrato de integração agroindustrial tem como causa o abastecimento do produtor integrado e a organização do mercado agrícola.

Em razão das diferenças em relação a natureza dos vínculos de integração agroindustrial nas cooperativas e indústrias processadoras, os problemas visualizados na integração contratual diferem da relação entre cooperado-produtor e cooperativa-integradora.

Assim, os mecanismos de contenção da dependência econômica e assimetria informacional criados pela Lei 13.288/2016 não se amoldam à realidade das cooperativas, marcadas pelos problemas de incentivo, que devem encontrar a solução na lógica própria do cooperativismo.

Portanto, as características próprias das cooperativas, que as tornam diferentes das demais organizações, também são razões para a exclusão das cooperativas do regime jurídico da integração agroindustrial fixado pela Lei 13.288/2016, que corretamente levou em consideração o cooperativismo na definição do contrato de integração agroindustrial, como determina o artigo 187, inciso VI, $C F$.

Com essa opção, o legislador manteve os custos transacionais do cooperativismo afastados das proteções específicas do contrato de integração agroindustrial, com a preservação da organização cooperativista como coordenadora da atividade produtiva transferida ao cooperado/produtor e organização vocacionada para atender ao bem-estar dos seus cooperados.

Além disso, o parágrafo único, do artigo $\mathfrak{1}^{\circ}$, da LIntegr também se justifica como comando destinado à garantir o adequado tratamento tributário previsto no artigo 146, III, "c", CF, para afastar a incidência do artigo 25 da Lei no 8.212/1991 às transações praticadas entre cooperativa e cooperado, muito embora a interpretação vigente seja contrária à natureza da operação e da intenção do legislador.

Com a edição da Medida Provisória no 899/2019, que modificou a redação do §3ํㅡ e incluiu os §§ 14 ao 16 no artigo 25 da Lei no 8.212/1991, a expectativa é de que haja pacificação da definição da base de cálculo na integração agroindustrial praticada por cooperativas, de modo a resguardar o "adequado tratamento tributário ao ato cooperativo".

Para trabalhos futuros, sugere-se a continuidade do estudo pelo enfrentamento dos mecanismos necessários para equacionar os problemas de incentivo nas cooperativas agroindustriais e o monitoramento da interpretação conferida à nova redação do artigo 25 da Lei no 8.212/1991 às cooperativas agroindustriais. 


\section{Referências}

BECHO, Renato Lopes. O conceito legal de ato cooperativo e os problemas para o seu "adequado tratamento tributário". In: BECHO, Renato Lopes. (coord.). Problemas atuais do direito cooperativo. São Paulo: Dialética, 2002.

BECHO, Renato Lopes. Tributação das cooperativas. 3. ed. rev. ampl e atual. São Paulo: Dialética, 2005.

BIALOSKORSKI NETO, Sigismundo. A nova geração de cooperativas e a coordenação de sistemas agroindustriais. In: BIALOSKORSKI NETO, Sigismundo. (org.). Workshop Internacional de Tendências do Cooperativismo: anais comemorativos 10 anos. Ribeirão Preto: FEARP/USP, 2008.

BIALOSKORSKI NETO, Sigismundo. Agronegócio cooperativo. In: BATALHA, Mário Otávio (coord.). Gestão agroindustrial. 1. v. 3. ed. São Paulo: Atlas, 2011.

BIALOSKORSKI NETO, Sigismundo. Aspectos econômicos das cooperativas. Belo Horizonte: Mandamentos, 2006.

BIJMAN, Joe. Vertical coordination in the agrifood suply chain: structure and strategy of the agricultural cooperative. In: ZYLBERSZTAJN, Décio; OMTA, Onno. (orgs). Advances in supply chain analysis in agri-food systems. São Paulo: Singular, 2009.

BRASIL. Coordenação-Geral de Tributação da Receita Federal. Solução de Consulta no 6026 - Disit. Disponível em: http://normas.receita.fazenda.gov.br/sijut2consulta/link.action?idAto=102261\&visao=anotado. Acesso em: 26. out. 2019.

BRASIL. Coordenação-Geral de Tributação da Receita Federal. Solução de Consulta no 11 - Cosit. Disponível em:

http://normas.receita.fazenda.gov.br/sijut2consulta/link.action?idAto=79703\&visao=anotado. Acesso em: 26.mai. 2019.

BRASIL. Projeto de Lei N. 330, de 2011 (do Senado Federal). Dispõe sobre a parceria de produção integrada agropecuária, estabelece condições, obrigações e responsabilidades nas relações contratuais entre produtores integrados e agroindústrias integradoras, e dá outras providências. Disponível em https://legis.senado.leg.br/sdleggetter/documento?dm=2950123\&ts=1543139502985\&disposition=inline. Acesso em: 02. mar. 2019.

BRASIL. Superior Tribunal de Justiça, Recurso Especial 248.073/RS, Ministro Relator Francisco Peçanha Martins, DJ 18/11/2002.

BUENO, Francisco de Godoy. Contratos agrários agroindustriais: analise à luz da teoria dos contratos típicos. São Paulo: Almedina, 2017.

CARROZZA, Antonio. Consideraciones sobre la tipificación del contrato agroindustrial. In: CARROZZA, Antonio; ZELEDÓN, Ricardo Zeledón. Teoría general e institutos de derecho agrario. Buenos Aires: Astrea, 1990. p. 321-331.

CASSI, Guilherme Helfenberger Galino. GONÇALVES, Oksandro Osdival. Os custos de transação no contrato de integração. Revista da AJURIS, v. 41, n. 136, p. 247-266, dez. 2014.

DINIZ, Gustavo Saad. A emenda do direito do agronegócio no projeto de Código Comercial. In: LIMA, Cíntia Rosa Pereira de; SAAD-DINIZ, Eduardo; MARRARA, Thiago. (coords.). O direito brasileiro em evolução: estudos em homenagem à Faculdade de Direito de Ribeirão Preto da Universidade de São Paulo. São Paulo: Almedina, 2017. 
DINIZ, Gustavo Saad. Curso de direito comercial. São Paulo: Atlas, 2019.

FRANKE, Walmor. Direito das sociedades cooperativas. São Paulo: Saraiva, 2009.

JANNARELLI, Antonio. Contractual relationships and inter-firm co-operation in the agri-food sector. Rivista di Diritto Alimentare. ano v, n. 4, n.p. out./dez. 2011. Disponível em: http://www.fao.org/uploads/media/JANNARELLI.pdf. Acesso em: 27. fev. 2019.

KOLLER, Fred E. Vertical integration of agricultural cooperatives. Journal of Farm Economics, v. 32, n. 4., nov., p. 1048-1058. 1950.

LAKATOS, Eva Maria; MARCONI, Marina de Andrade. Fundamentos da metodologia científica. 7. ed. São Paulo: Atlas, 2010.

MCNAUGHTON, Charles William. Ato cooperativo e tributação das sociedades cooperativas. In: SALOMÃO, Marcelo Viana Salomão; FORNECETTE, Rodrigo (coords.). Direito tributário cooperativo. São Paulo: MP Editora, 2007.

OSTROM, Elinor. Governing the commons: the evolution of institutions for collective action. Cambridge: Cambridge University Press, 2015.

PAIVA, Nunziata Stefania Valenza. Contratos agroindustriais de integração econômica vertical. Curitiba: Juruá, 2010.

PINHO, Diva Benevides; UTUMI, Américo; LAUSCHNER, Roque. Cooperativas agrícolas. In: PINHO, Diva Benevides (org.). Manual de cooperativismo. 4.v. Tipologia cooperativista. São Paulo: CNPq, 1984 .

PORRU, Paola. Riflessioni sulla causa dei contratti-agro-industriali. In: MASSART, Alfredo (Org.). Accordi interprofessionali e contratti agroindustrial: problema di inquadramento giuridico. Pisa: ETS, 1990.

RIZZARDO, Arnaldo. Contrato de integração nas atividades agrossilvipastoris. Revista de Direito Recuperacional e Empresa, São Paulo, v. 3, n.p, jan./mar., 2017.

SOPEÑA, Mauro Barcellos; ARBAGE, Alessandro Porporatti; VAZ, Fabiano Nunes. Projetos de lei sobre integração agroindustrial: a realidade brasileira. Revista de Politica Agricola, v. 25, p. 55-63, 2016. Disponível em: https://seer.sede.embrapa.br/index.php/RPA/article/view/1085/pdf. Acesso em: 24.12.2018.

SOUSA, Diego Neves de. AMODEO, Nora Beatriz Presno. MACEDO, Alex dos Santos. MILAGRES, Cleiton Silva Ferreira. A comunicação na articulação agroindustrial entre uma cooperativa central, suas cooperativas singulares e cooperados. Revista de Economia e Sociologia Rural, v. 52, p. 495514, jul./set. 2014.

SOUSA, Diego Neves de. MACEDO, Alex dos Santos. MILAGRES, Cleiton Silva Ferreira. COSTA, Michele Silva. Os desafios das cooperativas no sistema agroindustrial da cadeia produtiva do leite. Revista de Gestão e Organizações Cooperativas, v.4, n. 8, p. 123-140, jul./dez. 2017.

THAME, Antônio Carlos de Mendes; AMARO, Antônio Ambrósio. Relações contratuais de compra e venda de produtos agrícolas. In: PINHO, Diva Benevides (org.). Manual de cooperativismo. 4.v. Tipologia cooperativista. São Paulo: CNPq, 1984.

TORRES, Heleno Taveira. Tributação das cooperativas nos contratos de integração vertical. Conjur, 27. fev. 2019. Disponível em: https://www.conjur.com.br/2019-fev-27/consultor-tributario-tributacaocooperativas-contratos-integracao-vertical. Acesso em: 02.mar. 2019. 
UNIDROIT; FAO; FIDA. Guia jurídico sobre a agricultura contratual. trad. Iacyr de Aguilar Vieira, Kassia Watanabe, Nunziata Valente Paiva, Regel Antônio Ferrazza. Viçosa: Editora UFV, 2018. WALENDORFF, Rafael. Cooperativa quer isonomia para seus 'integrados'. Valor Econômico, 06. Mar. 2020. Disponível em: https://valor.globo.com/agronegocios/noticia/2020/o3/o6/cooperativaquer-isonomia-para-seus-integrados.ghtml. Acesso em: 06. mar. 2020.

WATANABE, Kassia. Relações contratuais no agribusiness. Tese (Doutorado em Direito) - Scuola Superiore di Studi Universitari e di Perfezionamento Sant'anna di Pisa, Classe Accademica di Scienze Sociali, Pisa, 2007.

WATANABE, Kassia; Lourenzani, Ana Elisa; BANKUTI, Sandra Mara Schiavi. Contract farming, a strange type of contract: more than obligation 'to give'. In: MARTINO, Gaetano; KARANTININIS, Konstantinos; PASCUCCI, Stefano; DRIES, Liesbeth K.E.; CODRON, Jean Marie. It's a jungle out there the strange animals of economic organization in agri-food value chains. Wageningen: Wageningen Academic Publishers, 2017. p. 177-196.

WATANABE, Kassia; PAIVA, Nunziata Stefania; LOURENZANI, Ana Elisa Bressan Smith. Contract farming in Brazil - an approach to Law and Economics. Revista de Direito FGV, v. 13, n. 1, p. 95-122, jan./abr. 2017.

WATANABE, Kassia; ZYLBERSZTAJN, Decio. Contract farming in the Brazilian agribusiness system: private institutions and State intervention. Uniform Law Review, Milano, v. 19, p. 459-478, 2014.

ZELEDÓN, Ricardo Zeledón. Integración vertical en agricultura y contrato agroindustrial. In: CARROZZA, Antonio; ZELEDÓN, Ricardo Zeledón. Teoría general e institutos de derecho agrario. Buenos Aires: Astrea, 1990. p. 309-320.

ZYLBERSZTAJN, Decio. Quatro estratégias fundamentais para cooperativas agrícolas. In: BRAGA, Marcelo José. REIS, Brício dos Santos. (orgs.). Agronegócio cooperativo: reestruturação e estratégias. Viçosa: Universidade Federal de Viçosa, 2005.

ZYLBERSZTAJN, Decio. SOUZA, José Paulo de. Poder de mercado e poder de contrato envolvendo integrados cooperados e não cooperados: percepções na cadeia de frango. In: Informações econômicas. São Paulo. v. 41. n. 7. jul. 2011. 